\title{
Arthur Walton Rowe, M.S., M.B., M.R.C.S., F.G.S.
}

BORN 27TH SHPTEMBER, $185 \mathrm{~S}$.

DiED 17TH SEPTEMBER, 1926.

The death of Dr. Rowe has removed from the ranks of British geologists a highly gifted amateur, whose contributions to the zonal study of the White Chalk are the most important that have been made since the publication of the classic memoir by Barrois in 1876. Rowe's keenness as a naturalist and collector led him at an early age to search for fossils in the districts that lay within easy reach of his home at Margate, and the sections in the Lower London Tertiaries near Herne Bay, the Gault of Folkestone, and the Lower Chalk between East Wear Bay and Shakespeare Cliff were hunting-grounds of equal interest to him. Later, his observations in the White Chalk of the Kent coast convinced him that many criteria for zonal differentiation and diagnosis that had previously been overlooked were to be found in the slow evolutionary changes observable by a critical eye in certain characters of the fossils. $\mathrm{He}$ devoted attention in particular to the evolution of the genus Micraster.

Rowe's pertinacity and scrupulous care as a collector enabled him to obtain abundant data well suited for his evolutionary studies, and the first-fruits of this work were embodied in his important paper on the genus Micraster, published by the Geological Society in 1899. This paper proved of great practical value in geological work, and showed, moreover, what could be achieved by careful collecting in an unbroken series of beds displaying relatively uniform conditions of sedimentation. It provided a stimulus to other investigators to apply the same methods in the study of different groups of fossils.

The work on Micraster was followed by comprehensive studies of the zones of the White Chalk as seen in the coastal sections in Kent and Sussex, Dorset, Devon; and Yorkshire, the results of which were published by the Geologists' Association (1900-4). The further paper on the zones of the White Chalk in the Isle of Wight, issued by the same Association in 1908, was framed on rather more elaborate lines, and includes an account of the chief inland sections. During the preparation of these papers, Dr. Rowe worked in conjunction with Mr. C. Davies Sherborn, to whose assistance he owed more than is generally realized. It is perhaps not too much to say that without Mr. Sherborn's encouragement and energetic help, the papers might have remained unpublished. They were written during hours of scanty leisure while Dr. Rowe was busily engaged in his professional duties. The field-work was carried out during spring and late autumn holidays; the examination of specimens and the writing of manuscripts was done chiefly between the hours of 10 p.m. and 1 a.m., after strenuous days of medical and surgical work. When we bear in mind the difficult conditions 
under which Dr. Rowe carried on his geological investigations, these papers must be regarded as a remarkable achievement. The value of four of them was enhanced by the beautiful photographs made by Professor H. E. Armstrong, in illustration of the chief sections described. The Geological Society recognized the importance of Dr. Rowe's work by the award to him of the Wollaston Fund in 1901, and the Lyell Medal in 1911.

In addition to other adverse circumstances, Dr. Rowe s occupation in hospital work during the War put an end to the publication of further results, although he continued his geological field-work from time to time, particularly in Norfolk. He devoted much time to his great zonal collection of Chalk fossils, which contains abundant proof of his skill in preparing delicate specimens and his care and method in arrangement and labelling. This fine collection, which so fully illustrates Rowe's published papers, has now been acquired by the British Museum (Natural History) and will be available for study. Its special value for stratigraphical work can only be fully retained if the collection is kept intact.

In his own special sphere of geological study Rowe showed a - masterly grasp, and to accompany him in his field-excursions was a rare pleasure as well as an education of great value. His keen powers of observation, his method, his enthusiasm, and his command of details significant in zonal work were remarkable. Lack of time was doubtless partly responsible for his somewhat limited outlook on geological problems as a whole. It was not that his mental predilections were narrow, for he showed enthusiastic interest in art, music, literature, horticulture, and antiquarian pursuits.

As a medical man, Dr. Rowe possessed in an exceptional degree those qualities which make for success. He had an unfailing charm of "manner, a personal magnetism, and a cheery optimism which endeared him to all whom he attended as physician or surgeon. Apart from his profession, he was apt to show a reticence and preoccupation which sometimes gave rise to misunderstanding. The present writer knew him for nearly thirty years as a staunch and unselfish friend.

F. L. Kitchin. 